\title{
Analytics of Antimony in Natural Water of Nanoparticle Platinum Electrode by Application Square Wave Voltammetry
}

\author{
Ahmad Khalaf Alkhawaldeh \\ University of Jordan, Department of Chemistry, Amman - 11942, Jordan. \\ E-mail: Ahm9140096@fgs.ju.edu.jo,Ahmad.alkawalda@yahoo.com
}

Phone: 00962787455167

\begin{abstract}
This study on the production of a modern natural water electrochemical antimony (II) test include the use of platinum platinum electrode electrodes. Antimony (II) was pre-concentrated on the modified electrode surface and adsorbed to the surface, oxidizing at $\mathrm{E}=-680 \mathrm{mV}$. Compared to the platinum electrode, the platinum nanoelectrode exhibited superior performance and, unexpectedly, received a higher electrochemical response. After 25 min of accumulation, time the best-defined anodic peak was obtained with $0.2 \mathrm{~mol} \mathrm{~L}^{-1} \mathrm{KNO}_{3} \mathrm{pH}$ 5.0. Using these parameters, the $\mathrm{L}^{-1} \mathrm{Sb}^{2+}$ calibration plot was linear over range 1 $=10^{-8}$ to $5 \times 10^{-6} \mathrm{~mol}$. The precision was tested by carrying out eight replicate measurements at a concentration of $2.5 \times 10^{-5} \mathrm{~mol}^{-1}$; the variance coefficient was $2.9 \%$. The method was applied to analyte determination in water samples from the river. Other metal ion attack on Sb's (II) voltammetric response has been studied. In the SEM image, the nanoparticle electrode was clearly observed and characterized by X-ray diffraction and cyclic voltammetry.
\end{abstract}

Key Words: Nanoparticle, Antimony, Platinum Electrode, Square Wave Voltammetry.

\section{Introduction}

Heavy metals such as as mercury, lead, and cadmium develop rapidly, particularly in rivers and near shore waters where waste from industry is released. They appear to center on all environmental matrices (Srivastav, 1994). In the general setting, mining, powdering, processing, casting, refining and metals usage resulted. Ingestion of heavily metal contaminated foods and beverages can affect the health of the general population (Cornelis et al, 2005).

Heavy metals were extensively investigated in this connection. Atomic adsorption spectrometry (AAS) procedures (Vale et al, 2001), ion chromatography techniques (Lin and Huang, 2017) and atomic emission spectrometry (AES) (Besteman et al, 1999) have been published. Such techniques however have some drawbacks, such as difficult operation, high maintenance costs, costly equipment that requires well regulated experimental conditions. In fact, heavy metal electrochemical identification on various electrical surfaces, including solid electrodes, was carried out (Laschi et al, 2006), microelectrodes (Strmčnik et al, 2019), Nafion-modified electrodes (Alkhawaldeh et al, 2020), and nanoelectrode (Hourani and Alkawaldeh, 2016).

Several researchers documented the use, with pulsation methods such as square-wave voltammetry and differential pulse voltammetry, of chemically modificed electrodes (CMEs) in electrocatalysis (Ghiaci et al, 2007). Therefore, this electrical research approach is less sensitive to the effects of matrix interference, a property of their performance in electroanalysis (Altweiq and Alkhawaldeh, 2019). The benefits of CMEs include a smaller history, a wide variety of available potentials, fast turnaround and simple production (Khedher et al, 2012).

Electrochemical research techniques are one of the main analytical chemistry approaches. This has been supported by the well-developed principle and modern microprocessor and computer equipment instrumentation (Cao et al, 2008). Electrochemical methods require re-searchers, in the check for the basic matter and in the analysis of impurities, to analyze and assess both macro and trace quantities of organic and inorganic compounds (Kokkinos et al, 2008). 
In the work discussed in this article, an appropriate method for the analytical determination of antimony $(\mathrm{Sb})$ in pure and natural water samples has been investigated with the advantage of the use of Platinum electrodes in conjunction with square wave voltammetry.

\section{Experimental}

Both chemicals were listed as reagents and used as approved. By diluting certain chemical compounds into high-purity Bi-distilled deionized water (BDW) system (Milli-Q water system), aquatic solutions had been prepared. Fisher Scientific also obtained antimony nitrate and potassium nitrate. Carbon paste (Carbon, Lorraine, 9900, French) was supplied.

A water solution path containing the combination of the platinum electrode used in this work, calcium nitrate and ammonium phosphate Symphysis. The average volume of the sample in the electrochemical cell was $20 \mathrm{~mL}$ in each trial. A scan electron Microscopes (SEM, Jeol JSM-5500) has been used to test the coated specimen.

One experiment was performed on the spectrometry of mediated plasma-atomic emissions (ICP-AES, Perkin-Elmer DV 3300). This contains a platinum electrode glass cell, the platinum counter electrode and the reference electrode $\mathrm{Ag} / \mathrm{AgCl} / 1 \mathrm{M}$ of $\mathrm{KCl}$.

\section{Analytical Procedure}

First of all, the electrode was submerged in an antimony solution, which produced a chemical accumulation in an open circuit for antimony ions. The electrode was then removed from the membrane, washed in water and relocated to the real voltammetric membrane in which only one electrolyte $\left(0.2 \mathrm{~mol} \mathrm{~L}^{-}\right.$ ${ }^{1} \mathrm{KNO}_{3}$ ) was present.

Different protocol in sample processing and in room temperature electrochemical experiments were performed. The same electrochemical systems mentioned above have been used for this calculation before and after immersion in antimony (II)-containing solution. For AC voltage of $5-10 \mathrm{mV}$ at $0 \mathrm{mV}$ the frequencies from $100 \mathrm{KHz}$ to $10 \mathrm{MHz}$ can now be calculated.

After 30 minutes of exposure, computer programs automatically test measurements made at rest potentials. Experiments have been carried out using the open circuit square-wave voltammetric system by deposit of the antimony target (II). At the potential -1.0 to $-0.4 \mathrm{~V}$ the accumulated metal was then anodized with a phase potential of $25 \mathrm{mV} ; 5 \mathrm{mV}$ amplitude, $5 \mathrm{sec}$ amplitude and $1 \mathrm{mV} \mathrm{s}^{-1}$ scan rate.

\section{Results and Discussion}

The SEM micrograph with E potential $=14.5 \mathrm{~V}$ is seen in Figure 1 . The powder layer showed a well separated, homogeneously dispersed porous nanostructure over the earth. It is confirmed by the EDX sequence of $25.8^{\circ}<31.6^{\circ}<32,1^{\circ}<32,7^{\circ}$ and $34^{\circ}$ platinum electrode, indicating the usual diffraction peaks. 


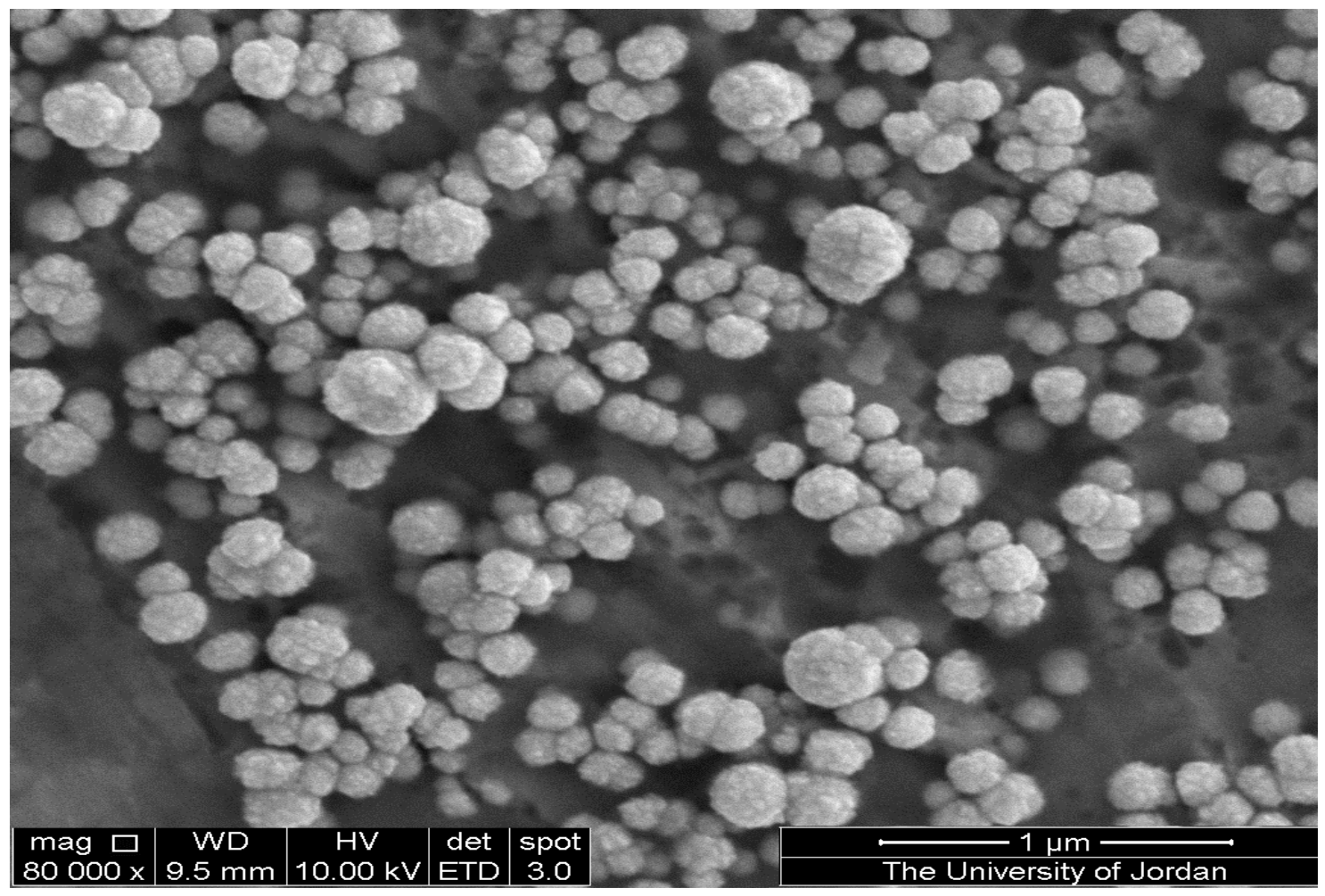

Figure 1; Scanning electron micrograph of platinum nanoelectrode.

Figure 2 indicates the platinum electrode concentration of Antimony (II). With cyclic Voltammetry $(\mathrm{CV})$, the voltammograms were obtained at an appropriate scan rate of $100 \mathrm{mV} \mathrm{s}-1$. Before a preconcentration phase in Sb (II) solution, the base curve, showing no point, was obtained. As shown in Figure 2, after the pre-concentration phase the peak current revealed that the $\mathrm{Sb}$ (II) had been removed from the bulk solution by platinum nanoelectrode. 


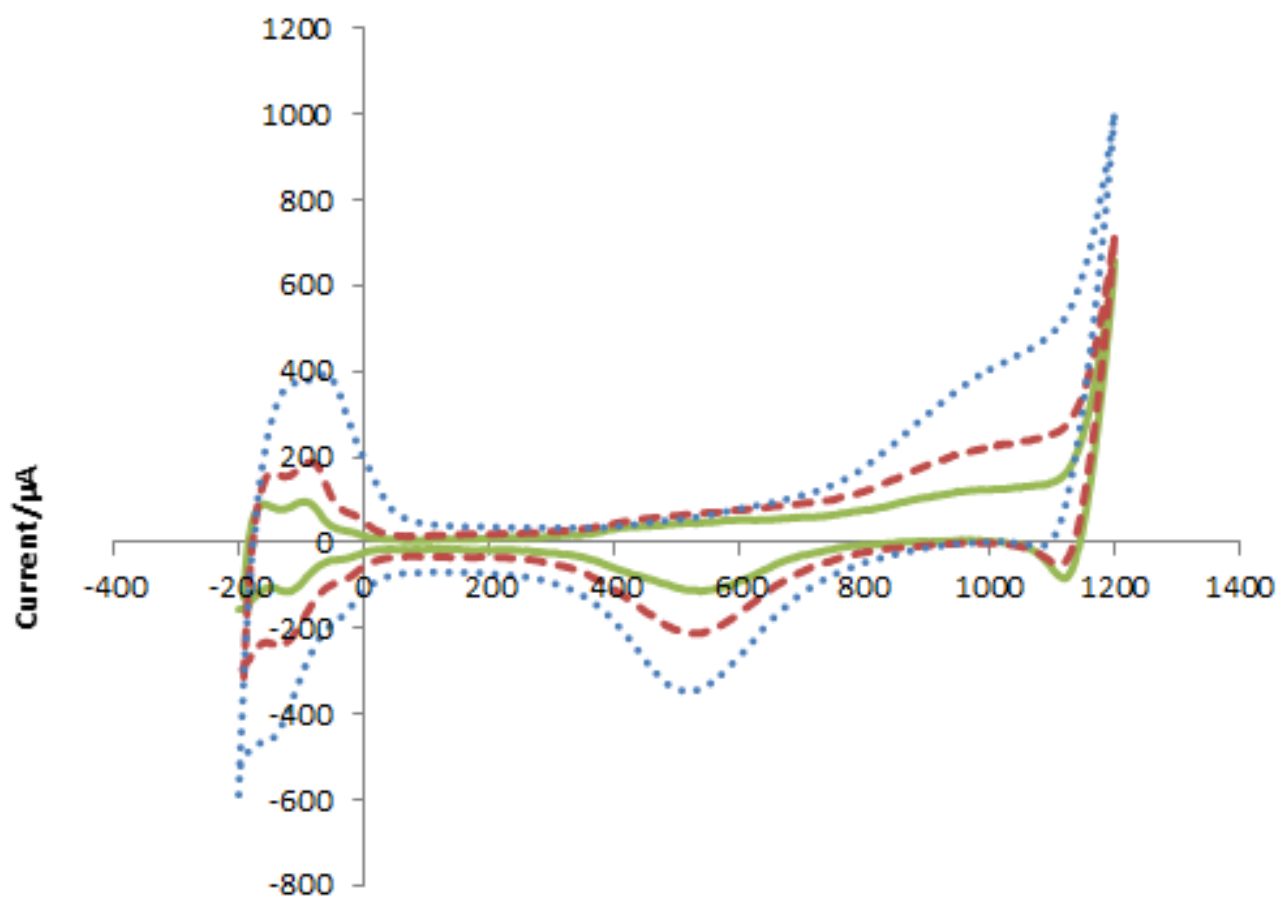

Potential /V vs Ag/Agcl/[Cl- $]=0.1 \mathrm{M}$

Figure 2; cyclic voltammograms of nanoparticle platinum electrode before and after incubation with Antimony (II). During $30 \mathrm{~min}$; supporting electrolyte is $0.2 \mathrm{~mol} \mathrm{~L}^{-1} \mathrm{KNO} 3$, $\mathrm{pH} 5.6$; the scan rate was $100 \mathrm{mV} \mathrm{s}-1$. [Sb (II)] $=310^{-4} \mathrm{~mol} \mathrm{~L}^{-1}$.

Figure 3 displays the platinum nanoelectrode impedance diagram in 3X10-4 mol L-1 Antimony (II) solution, prior to and after preconcentration phase. The $0.2 \mathrm{~mol} \mathrm{L-1} \mathrm{KNO3} \mathrm{electrolyte} \mathrm{obtained} \mathrm{similar}$ diagrams. The data demonstrate explicitly that when the Pt is subjected to antimony (II), its capacitance at the interface is increased. In the event of adsorption on the electrode surface, this finding is in line with the literature (Alshamaileh et al., 2016). As part of an optimized process that results in electrolytic reduction of the heavy metal in the changed coating, we offer empirical evidence for the Sb (II) ad absorption on the ground. The observed decrease of the resistance to charge transfer often results in the conductivities of the additive electrode that can be clarified with the inclusion of Antimony on the surface of the electrode.

The layer powder on platinum surfaces was analyzed by cyclic voltammetry on the electrode before and after the pre-concentration stage in antimony solution (Figure 3). As seen in Figure 4, Sb (II) has been observed with a pair of stable and well-defined redox peaks. This findings suggest that after pre-concentration in the antimony solution $\mathrm{Sb}$ (II) is present in or / and appetite coating platinum electrodes. The result reveals that the nanoparticle is an important element in the Sb (II) accumulation cycle on the platinum electrode surface, indicating the systemic manipulation of anodic surface processes by square wave voltammetry with some critical advantages.

Platinum nanoelectrodes is immersed in antimony (II) solution $\left(2.0\right.$ to $\left.\times 10^{-3} \mathrm{~mol} \mathrm{~L}^{-1}\right)$. Double distilled water washed and then brought to $0.2 \mathrm{~mol} \mathrm{~L}^{-1} \mathrm{KNO}_{3}$ for examination. The Pt immersion time in Sb (II) solution had a significant effect on the surface state and the impedance of the electron transmission. It can be shown that with the introduction of the adsorption time, the diameter of the semicircle has decreased 
to greater frequencies. There was no dramatic improvement at the interface electron transmission resistance, suggesting that $\mathrm{Sb}$ (II) adsorption exceeded saturation point, when the soaking time in the antimony solution was more than $20 \mathrm{~min}$.
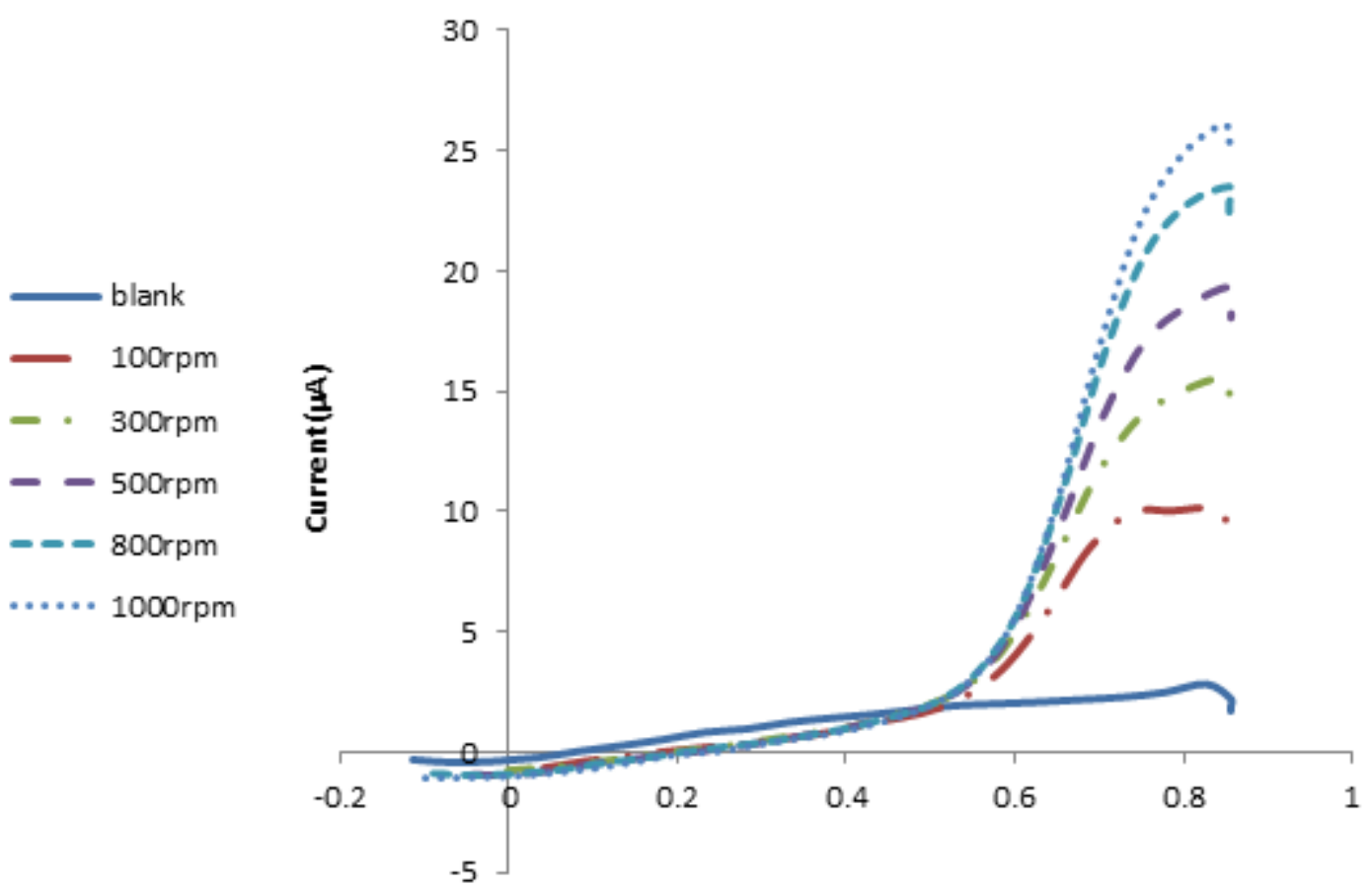

Figure 3; cyclic voltammograms of Antimony (II) at different concentration in the solution.

The test plot produced in the above conditions ( $\mathrm{pH} 6.5,0.2 \mathrm{~mol}^{-1} \mathrm{l}^{-1}$ nitrate, $25 \mathrm{~min}$ deposition time) as shown in Figure 4. Linear reaction to a sensitiveness (path) of $0,0301 \mu \mathrm{A}$ per antimony $1 \mu \mathrm{mol}\left(\mathrm{R}^{2}=0,991\right)$ was reached in platinum nanoelectrodes to $20 \mathrm{~mol} \mathrm{~L}^{-1}$. The lower detection limit (DL, 3) and the quantitative limit (QL, 3), which were five times the normal variance of the results obtained for a white person, were 8.85 10-8 mol. $^{-1}$ and 9.3510 to 7 mol.1-1 respectively.

The tests of these antimony ultra-traces are shown to be extremely suitable in water samples where a maximum suggested residual stipulation is $10 \mu \mathrm{g} / \mathrm{kg}$ suggesting that antimony (II) can be studied in natural water samples (Almatarneh et al., 2019). 


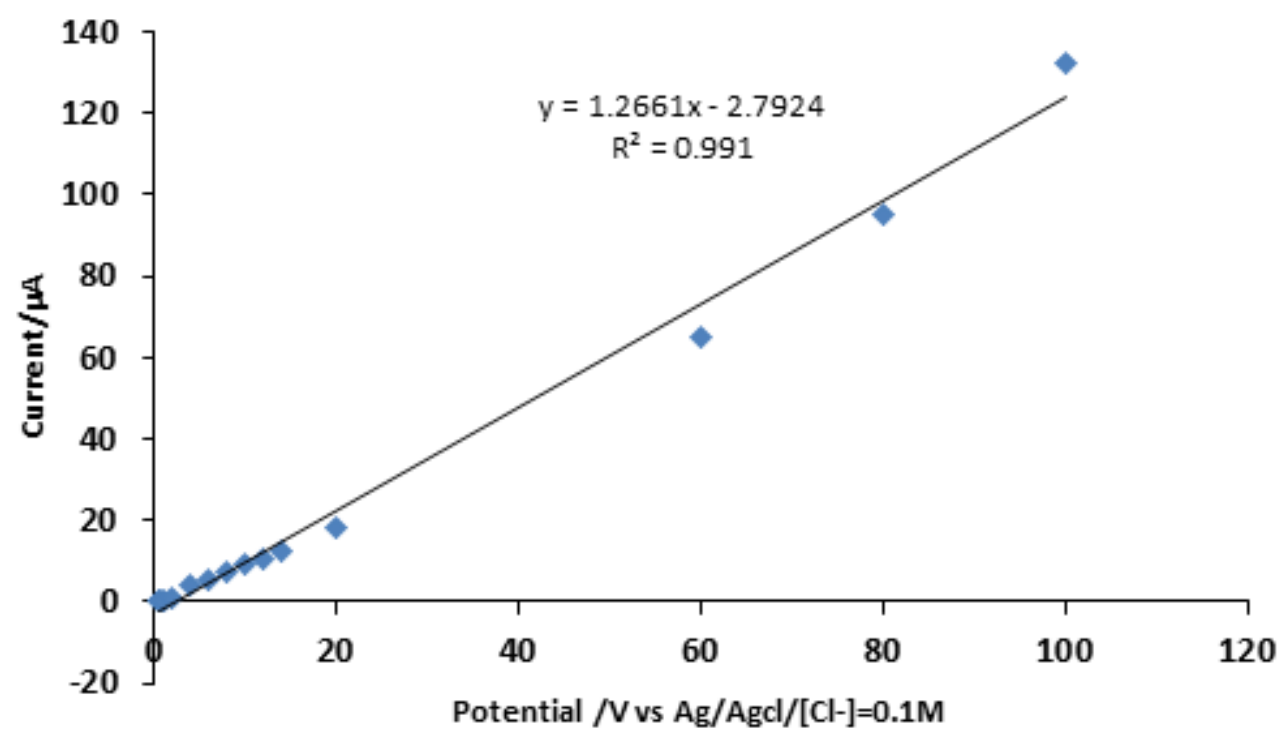

Figure 4; The calibration plot generated using the optimum conditions determined at $\mathrm{pH} 6.5$ and $0.2 \mathrm{~mol}^{-1}$ Antimony nitrate.

The $\mathrm{D}_{\mathrm{L}}$ and $\mathrm{Q}_{\mathrm{L}}$ obtained in the present test are equivalent to the literary standards. It should be noted. It was better than the bismuth video (Krishan and Alkhawaldeh, 2019). By changing the Pt ratio, the detection limit can be increased. Especially by increasing the surface area of the multiplier, the detection limit can be greatly improved. The relative standard deviation of eight consecutive measurements, which showed an outstanding reproducibility, was 2.9 percent for $2.5 \times 10-5 \mathrm{~mol} \mathrm{~L}^{-1}$ antimony. Moreover, it was examined the stability of the modified electrode. In the $\mathrm{pH} 6.5$ of $2.5-\times 10^{-5} \mathrm{~mol} \mathrm{~L}^{-1}$, the peak current was measured every day (Chen et al., 1997). There was no apparent reduction of the current response over three days and a decline of $10 \%$ after six days, which then remained almost unchanged.

\section{Conclusions}

It was shown that with cyclic and square wave voltammetry, one well-defined anode peak could be achieved at a power of $0.74 \mathrm{~V}$ versus $\mathrm{Ag} / \mathrm{AgCl}$. The $\mathrm{Sb}$ oxidation accumulated on platinum nanoelectrode takes place. Antimony (II) detection limit of 8.85 10-8 mol L-1 was much higher than those mentioned in the literature when experimental conditions for square wave voltammetry were optimized, and this sensor displayed an broad linear reaction range, good sensitivity, and reproductively. Nevertheless, nanoparticle platinum was the only electro catalyst that would perform the reaction at an acceptable rate. This led to a substantial search for the theoretical electro-catalysis of the square wave voltammetry.

\section{References}

Alkhawaldeh, A. K., M.Krishan, M., Altwaiq, A., Dabaibeh, R. N. (2020). Preparation of Nanostructured/ Microplatinum Surfaces by Application of a Square Wave Potential Regime for Methanol Oxidation. Eurasian Journal of Analytical Chemistry, 15(1), emEJAC-00362. 
Al-Khedher, M. A., Pezeshki, C., Mchale, J. L., \& Knorr, F. J. (2012). Empirical Modeling of Nanoindentation of Vertically Aligned Carbon Nanotube Turfs using Intelligent Systems. Fullerenes, Nanotubes and Carbon Nanostructures, 20(3), 200-215. doi: 10.1080/1536383x.2010.542590.

Almatarneh, M. H., Elayan, I. A., Al-Sulaibi, M., Khawaldeh, A., Saber, S. O. W., Al-Qaralleh, M., and Altarawneh, M. (2019). Unimolecular Decomposition Reactions of Propylamine and Protonated Propylamine. ACS Omega, 4(2), 3306-3313. doi: 10.1021/acsomega.8b02792.

Alshamaileh, E., Al-Sulaibi, M., Al-Khawaldeh, A., Almatarneh, M., El-Sabawi, D. and Al-Rawajfeh, A. (2016), "Current status of nanotechnology in Jordan", World Journal of Science, Technology and Sustainable Development, Vol. 13 No. 2, pp. 66-81. https://doi.org/10.1108/WJSTSD-01-2016-0001.

Altweiq, A. and Alkhawaldeh, A (2019). The Determination of Some Heavy Metals in Different Selected Diets. Eurasian Journal of Analytical Chemistry, 14(4), emEJAC-00326.

Besteman, A. D., Bryan, G. K., Lau, N., \& Winefordner, J. D. (1999). Multielement Analysis of Whole Blood Using a Capacitively Coupled Microwave Plasma Atomic Emission Spectrometer. Microchemical Journal, 61(3), 240-246. doi: 10.1006/mchj.1999.1705.

Cao, L., Jia, J., \& Wang, Z. (2008). Sensitive determination of Cd and Pb by differential pulse stripping voltammetry with in situ bismuth-modified zeolite doped carbon paste electrodes. Electrochimica Acta, 53(5), 2177-2182. doi: 10.1016/j.electacta.2007.09.024.

Chen, Wright, J. V., Conca, J. L., \& Peurrung, L. M. (1997). Effects of pH on Heavy Metal Sorption on Mineral Apatite. Environmental Science \& Technology, 31(3), 624-631. doi: 10.1021/es950882f.

Cornelis, R., Caruso, J. A., Crews, H., \& Heumann, K. G. (2005). Handbook of Elemental Speciation: Species in the Environment, Food, Medicine and Occupational Health. Hoboken: Wiley.

Ghiaci, M., Rezaei, B., \& Kalbasi, R. (2007). High selective SiO2-A12O3 mixed-oxide modified carbon paste electrode for anodic stripping voltammetric determination of $\mathrm{Pb}(\mathrm{II})$. Talanta, 73(1), 37-45. doi: 10.1016/j.talanta.2007.02.026.

Hourani, M. K. and Alkawaldeh A. (2016). Synergistic Effects of Bismuth Adatoms on Electrocatalytic Properties of Electrodeposited Nanostructured Platinum Electrodes. International Journal of Electrochemical Science, 3555-3566. doi: 10.20964/110434.

Kokkinos, C., Economou, A., Raptis, I., \& Efstathiou, C. E. (2008). Lithographically fabricated disposable bismuth-film electrodes for the trace determination of $\mathrm{Pb}$ (II) and $\mathrm{Cd}$ (II) by anodic stripping voltammetry. Electrochimica Acta, 53(16), 5294-5299. doi: 10.1016/j.electacta.2008.02.079.

Krishan, M.; Alkhawaldeh, A.; Soliman, A. (2019). Development of Nitride-Sensors for Monitoring in Control Systems. Preprints, 2019050227.

Laschi, S., Palchetti, I., \& Mascini, M. (2006). Gold-based screen-printed sensor for detection of trace lead. Sensors and Actuators B: Chemical, 114(1), 460-465. doi: 10.1016/j.snb.2005.05.028.

Lin, S.-L., \& Huang, W.-C. (2017). Chelation Therapy Has a Beneficial Effect in Ultrasonic Endothelial Function in Patients with Elevated Serum Lead or Cadmium Levels. Ultrasound in Medicine \& Biology, 43. doi: 10.1016/j.ultrasmedbio.2017.08.1930. 
Srivastav, R. (1994). Treatment of chromium and nickel in wastewater by using aquatic plants. Water Research, 28(7), 1631-1638. doi: 10.1016/0043-1354(94)90231-3.

Strmčnik, E., Majdič, F., \& Kalin, M. (2019). Influence of a Diamond-Like Carbon-Coated Mechanical Part on the Operation of an Orbital Hydraulic Motor in Water. Metals, 9(4), 466. doi: $10.3390 /$ met9040466.

Vale, M., Silva, M., Welz, B., \& Lima, É. (2001). Determination of cadmium, copper and lead in mineral coal using solid sampling graphite furnace atomic absorption spectrometry. Spectrochimica Acta Part B: Atomic Spectroscopy, 56(10), 1859-1873. doi: 10.1016/s0584-8547(01)00336-6. 